\title{
Oral iodine supplementation in very low birth weight infants. Thyroid function and Neurodevelopmental follow up at 24 months. A Randomized Clinical Trial
}

Susana Ares ( $\square$ susana.ares@salud.madrid.org )

Hospital Universitario La Paz Hospital Infantil https://orcid.org/0000-0003-3801-9391

BELEN SAENZ-RICO

UCM: Universidad Complutense de Madrid

JUAN ARNAEZ

Centro Hospitalario Burgos: Hospital Universitario de Burgos

Jesus Diez-Sebastian

La Paz University Hospital: Hospital Universitario La Paz

Felix Omeñaca

La Paz University Hospital: Hospital Universitario La Paz

JUAN Bernal

CSIC: Consejo Superior de Investigaciones Cientificas

\section{Research Article}

Keywords: hypothyroxinemia, preterm infants, thyroid, neurodevelopment, iodine deficiency

Posted Date: March 26th, 2021

DOl: https://doi.org/10.21203/rs.3.rs-316884/v1

License: (9) (i) This work is licensed under a Creative Commons Attribution 4.0 International License.

Read Full License 


\section{Abstract}

The trace element iodine $(I)$ is essential for the synthesis of thyroid hormones. Premature babies need $>30 \mu \mathrm{g} \mathrm{I} / \mathrm{kg} /$ day (ICCIDD recommendations). Neonates and especially preterm infants are a population at risk of suffering the consequences of iodine deficiency, because of the impact of neonatal hypothyroxinemia on brain development. The main aim of this project is to prevent the mental retardation and increased risk of cerebral palsy of premature infants, which is partially caused by neonatal hypothyroxinemia. We gave Oral iodine supplementation in very premature babies during the neonatal period.

Population: we included 94 infants born <1500g. Intervention group: we administered $30 \mu \mathrm{g} \mathrm{I} / \mathrm{kg} /$ day of iodine in oral drops to 47 infants from first day of life until hospital discharge. Control group: 47 infants without supplements. The study was approved by the Ethics Committee. Samples of different formulas, maternal milk was kept for the determination of the iodine content. Interventions: Blood, food and urine samples (collected at 1, 7, 15, 21, 30 days after birth and at discharge). Measurements: milk and urine for iodine determination (Benotti method). Blood samples: for thyroid hormones (T4, free T4, T3 and TSH) and tyroglobulin. Their neurological development was assessed at 2 years of age (Bayley Test).

lodine content of mothers' breast milk: 15 (5.0) $\mu \mathrm{g} \mathrm{I} / \mathrm{dL}$ (range 1-60); Infants in the supplemented group reached the recommendations from the first days of life. Infants in the control group did not reach the recommended intake of iodine to 60 days of life. We found a positive relation between iodine intake and the concentrations of thyroid hormones until 60 days of life.

Conclusions: Thyroid function is related to iodine intake in preterm infants. Breast milk appears to be the best source of iodine for the premature infant. Preterm babies on formula preparations and with exclusive parenteral nutrition are at high risk of iodine deficiency. Therefore, supplements should be added if iodine intake is found to be inadequate.

\section{Introduction}

lodine is a trace element which is essential for the synthesis of thyroid hormones. Premature babies need $>30 \mu \mathrm{g} \mathrm{I} / \mathrm{kg}$ / day (International Council for the Control of Iodine Deficiency Disorders recommendations ICCIDD) (1)

The thyroid hormones, thyroxine $\left(T_{4}\right)$ and 3,5,3'-triiodothyronine $\left(T_{3}\right)$, are necessary for adequate growth and development throughout fetal and extra-uterine life during the first years of life.

Their effects of on the central nervous system are mediated by the regulation of the expression of genes that synthesize proteins implicated in: cerebral neurogenesis, neuronal migration and differentiation, axonal out-growth, dendritic ontogeny and synaptogenesis, cerebellar neurogenesis, gliogenesis and myelinogenesis. lodine deficiency may contribute to hypothyroxinemia and is recognised as cause of preventable mental retardation $(2,3,4)$ 
Neonates and preterm infants are a population at risk of suffering the consequences of iodine deficiency, because of the effects of the resulting neonatal hypothyroxinemia on brain development.

Transient hypothyroxinemia of prematurity (THOP) is characterized by low levels of serum thyroxine (T4) and tri-iodothyronine (T3), but normal thyroid stimulating hormone (TSH) levels until up to 6 weeks (wk) (evident in $41 \%$ of infants under 27 weeks gestation and in $23 \%$ of infants between $28-30$ weeks gestation) $(5,6,7,8,9)$.

The ethyology of transient hypothyroxinaemia may have contributions from the withdrawal of maternalplacental thyroxine transfer, hypothalamic-pituitary-thyroid immaturity, developmental constraints on the synthesis and peripheral metabolism of iodothyronines, iodine deficiency, and non-thyroidal illness.

The studies realized in the previous years in premature babies of 27-36 weeks of gestacional age, in the Neonatal Unit of La Paz revealed clearly that these infants have very low levels of free thyroxin (FT4) and of tri-yodo-thyronin (T3), compared with those of term newborns. The mental development has been studied at the age of 4 of age, being low in those children who had lower concentrations during the postnatal period, especially if this situation extended during the first two months of life. A subsequent study was performed in premature babies of minor gestacional age ( $<30$ weeks), but fed on formulae with higher iodine content. The mental development has been studied at the age of 6, 12, 18 and 24 months of age. A preliminary evaluation of the results indicates that the children with more problems of development keep on being those who had a lower iodione intake (10-23).

Parenteral nutrition is used in the clinical practice in all the immature newborn babies immediately in the first hours of life. At present the preparations used for the feeding parenteral in newborn babies present a content of iodine of 1 microgram for $\mathrm{ml}$. (24) and the recommendations of administration of iodine by route parenteral were established a few years ago in 1 microgram $/ \mathrm{kg} /$ day, being these quantities lower than the recommendations for oral route, possibly being based on the possibility of toxicity of the iodine by parenteral route. In absence of other sources of iodine, the newborn babies who are fed on parenteral nutrition present a deficiency of this micronutrient.

In pilot studies it has been described that the parenteral supplementation with quantities of iodine of 30 microgr/KG/day produces positive balance in the newborn baby, these are sure quantities and they do not produce side effects $(9,25)$. There are not at present preparations with iodine content higher than 1 $\mathrm{microgr} / \mathrm{ml}$. The parenteral supplementation of iodine needs an intravenous route, adds the maintenance of the sterility, there is more risk of infection and needs more sanitary personnel for maintenance.

These factors lead us to think that the administration of supplements by enteral route (oral drops) is effective, easier to administer, it is cheaper and does not exhibit the patient to major risks. The enteral supplementation of iodine has theoretically many advantages. Prevention of iodine deficiency and follow-up is recognized as a priority. The number of extremely low birth weight (ELBW) infants is high. Correction of their iodine deficiency and hypothyroxinemia and its consequences appears, to be an intervention with promising possibilities. Future research would be facilitated if preterm babies were 
followed during their stay in intensive care units with respect to their iodine nutrition and thyroid function as carefully as they are followed for other organ functions. Our aim is to determine, through a randomized controlled trial, whether nutritional supplementation with iodine solution via oral route (as a drop in the mouth) enables extreme preterm infants to achieve a positive iodine balance.

\section{STUDY DESING:}

We conducted a study of thyroid hormones in infants under $1500 \mathrm{~g}$ of birth weight. The study was designed as a longitudinal clinical trial, one group of infants with iodine supplements and a control group. Enrollment period: January 2007 - December 2009. 47 subjects were enrolled in the Control group (no supplements). 47 subjects were enrolled in the lodine supplemented group ( $30 \mu \mathrm{g} / \mathrm{kg} / \mathrm{day}$ of Potassium lodine (SSKI) in oral drops). Treatment period: All treatments start within 24 hours after birth. Every study subject receives the supplement during hospitalization until discharge. Parental written consent was obtained for each study subject. Parents and clinicians were not blind from treatment assignment throughout the entire study period. The study was approved by the Ethics Committee and by the Institutional Review Boards of the enrolment center (University Hospital LA PAZ, Madrid, Spain). Excluded were mothers less than 18 years old, mothers with thyroid disease or reported substance abuse (i.e., alcoholism or use of heroin or methadone, as these substances can interfere with hormone transport in serum) and newborns with major congenital malformations or if death was expected within 48 hours.

\section{Intervention}

We used Potasium lodine in oral drops (Babyodo $30^{\mathrm{m}}$. Dietetic food, watery solution of contained iodine $30 \mathrm{mcg}$ for $0,5 \mathrm{ml}$. Babyodo $90 \mathrm{~m}$ : Dietetic food, watery solution of contained iodine $90 \mathrm{mcg}$ for $1,5 \mathrm{ml}$. LITAPHAR Labs Pharmaceuticals).

Randomization was done by a web-based computer program, which balanced gestational age and sex. The iodine drops were administered from postnatal day 1 to postnatal day at discharge. We delivered either as oral drops or in oral submucosa. All infants in the supplemented group received a dose of 30 microgr $/ \mathrm{Kg} /$ day, independently of iodine intake received by milk or parenteral solutions.

During hospitalization, a daily evaluation of the intake was done.

\section{Methods}

Serial blood and urine specimens were collected on day $0,3,7,14,21,42,56$, and at discharge. Samples of different milk formulas and maternal milk was kept for the determination of the iodine content. Thyroid hormone testing: Free T4 (FT4) was measured using the equilibrium dialysis technique and the other hormones by standard immunoassay technology (Roche Diagnostics). The concentration of lodine in formula and milk samples was determined by modifications of chloric acid method Benotti and Benotti (28)

\section{Clinical definitions and management strategies}


Necrotizing enterocolitis was recorded if greater than Bell's stage II (at least proven by abdominal X-ray), retinopathy was recorded of prematurity as greater than stage III in either eye and chronic lung disease was recorded as oxygen requirement at 36 weeks to keep oxygen saturations greater than $88-92 \%$. Cranial ultrasounds were made throughout the hospital stay, and germinal matrix haemorrhages and white matter damage were scored according to the extremely low gestational age neonates (ELGAN) $(4,20,21)$.

\section{lodine precautions}

The study protocol called for avoidance of iodinated skin cleansers for antisepsis as excess exposure to iodine suppresses thyroid hormone synthesis. Instead, alcoholic chlorhexidine (2\%) was used for skin disinfection

\section{Data monitoring}

Clinical status and infant growth were recorded daily for two weeks and once per week thereafter in a web-based spreadsheet until hospital discharge. Cranial ultrasound imaging was conducted on postnatal days 1-3, 7-10 and after at least 4 weeks and was interpreted by a single radiologist, masked to the study arm.

\section{Neurodevelopmental follow-up}

At the corrected age of two years, surviving children and their parents were invited to the follow-up clinic. Development was assessed using the Bayley Scales of Infant and Toddler Development, third edition (BSITD III) $(26,27)$. Trained psychologists masked to the study groups administered the cognitive and motor scales. Assessment was ended in year 2012.

The cognitive scale assesses abilities such as sensorimotor development, manipulation, object relatedness, concept formation, memory, and simple problem solving, while the motor scale consists of fine motor (grasping, perceptual-motor integration, motor planning, and speed) and gross motor (sitting, standing, locomotion, and balance) subtests. The cognitive outcome is reported as the composite cognitive scale, which has a mean of 100 and a standard deviation of 15 . Scaled scores are used for the Fine and Gross Motor scores separately, which have a mean of 10 and range from 1 to 19 . Children were also assessed by blinded neuro-paediatricians for cerebral palsy (CP). The severity of CP was scored using the Gross Motor Function Classification System (GMFCS).

Moderate to severe delay in cognitive development was defined as a developmental age of more than six months below the corrected age at testing.

All infants were assessed for Auditory Evoked Potentials at 6 months of age.

\section{Statistical analyses}


For analyses of differences between the study arms, we used both parametric and nonparametric tests. Thus, analysis of variance and the Kruskal-Wallace test were used for continuous variables, and for dichotomous variables, the chi-squared test or Fisher exact test were used. We report findings for the parametric tests. We examined cognitive and motor scores and then we made a combined measure of adverse outcomes and/ or moderate to severe cognitive delays using the BSITD III (a score on these tests of greater than one SD below the mean). Whenever it is stated that a certain variable was higher, or lower, for different groups, or that correlations existed between the variables, it is implicit that the differences or correlation coefficients were statistically significant, at $\mathrm{P}<0.05$, or less for statistical analyses, SPSS software version 18 was used.

\section{Results}

The parents of 9 children could either not be traced or refused follow-up. Follow-up results were thus available for 89 of the children.

No differences were found in demographic and birth characteristics between groups (Table 1).

lodine content in breast milk was analyzed. The mean iodine content of mothers' breast milk was 15 (5.0) $\mu \mathrm{g} \mathrm{I/dL}$ (range 1-60). We evaluated the iodine intake of premature infants. After statistical analysis, no significant differences in calories received, volume of parenteral nutrition and breast milk volume between groups were observed.

Children who were supplemented, had a higher volume of breast milk at discharge $(p<0.05)$ compared to children in the control group.

Significant differences were found in the iodine intake. Children the supplemented group had the recommended iodine intake compared to the control group. Children in the supplemented group reached the recommendation of 30 micrograms / $\mathrm{kg}$ / day from the first days of life. Children in the control group did not reach the recommended amount of iodine until 60 days of life (Table 2). Children with exclusive parenteral nutrition in the control group had an intake below the recommendations.

The clinical course during supplementation was comparable between the two groups. No adverse events were found. lodine supplements have been very well tolerated by subjects.

lodine amount excreted in the urine was evaluated. The iodine concentrations in urine showed variable results. Children in supplemented group had higher urinary iodine excretion in control group at 15 and 30 days of life. Children in the supplemented group had significantly higher urine excretion in children not supplemented (Table 3 ).

\section{Thyroid function:}

Concentrations of thyroid parameters were evaluated. No group differences in hormones at 2, 7, 15, 21, 45, 60 days of life were found. Children in control group had higher TSH levels at 30 days of life. 
All infants in both groups presented hypothyroxinemia ( $\mathrm{T} 4$ below $10 \mu \mathrm{g} / \mathrm{dl}$ ) during the first 30 days of life.

Compared to the control group, we found a positive relation between iodine intake and the concentrations of thyroid hormones. T3 (Figure 1) and T4 (Figure 2) were directly related to the iodine intake at 7, 21, 30 and 60 days of life $(p<0.0076$; correlation coefficient $=0.42 ; p<0.05$; correlation coefficient $=0.32)$ was higher in the control group at 30 and 60 days of life and indirectly related to iodine intake (Figure 3 ).

We found a positive relation between intake of iodine at 7 days and the concentrations of total T4, at 21 days and concentrations of total T4 and T3, at 30 days and concentrations of total T4, T3, T4 and TSH, at 60 days and TSH levels.

\section{lodine intake, excretion and thyroid function related to neonatal diseases}

lodine intake, iodine excretion and thyroid function were analyzed with respect to the presence or absence of pathology in the neonatal period. The children in the control group presented the same frequency of diseases than children in supplemented group. Infants who presented hyaline membrane disease had lower concentrations of total T4 at 2 days of life and lower T3 concentrations at 21 days of life $(p<0,05)$. Subjects who presented patent ductus arteriosus, presented a higher iodine excretion than children without ductus during the first week of life and presented lower concentrations of total T4 and lower T3 concentrations at 2 and 7 days and lower free T4 concentrations at 7 days of life $(p<0,05)$. Infants with cerebral haemorrhage had lower free T4 concentrations than infants without bleeding. Infants who presented retinopathy had an iodine intake lower than infants without retinopathy at all ages. Subjects with severe retinopathy presented lower free T4 concentrations on 2 and 21 days of life. Children who presented severe anemia at birth had lower concentrations of total T4 at 2 days of life.

\section{Neurodevelopmental Evaluations}

Children were evaluated at 24 months of corrected age on the Mental Development Index (MDI) and Psychomotor Development Index (PDI).

There was no significant correlation between the scores at 24 months and total and free T4, and T3. We did not found significant correlations between the scores and gestational age, weight, height and cephalic perimeter at birth. Gestational age was not a predictive factor for alterations in neurodevelopment. We did not find any difference between infants with hyaline membrane disease, need of mechanical ventilation during the neonatal period and necessity of treatment with dopamine. There were no differences between girls and boys. We analyzed the neurodevelopmental scores in children who presented very low T4 levels $(<4 \mu \mathrm{g} / \mathrm{dl})$ during the first 30 days of life, and there were no significant correlations.

However lower expressive language developmental scores at 24 months was related to low levels of iodine excretion ( $<100$ micrograms /L) during the first four weeks of life, corrected for gestational age $(p<0.01)$. 


\section{Discussion}

Our trial reported no significant difference in any neonatal morbidity in preterm infants supplemented with oral iodine $30 \mu \mathrm{g} / \mathrm{kg} /$ day. All infants in supplemented group and control group presented transient hypothyroxinaemia during the first 30 days of life. Researchers hypothesise that infants born below 1500 g. may benefit from iodine supplementation. But taking into account our results, the intervention with oral iodine was not enough for avoid hypothyroxinemia of prematurity in very low birth weight infants included in the trial.

However, neurodevelopmental follow up was adequate so that conclusions can be made for long term effects. The dose of iodine $30 \mu \mathrm{g} / \mathrm{kg} /$ day was the recommendation reported by ICCIDD based on different previous studies. However, there was no measurable effect on avoiding hypothyroxinaemia of prematurity during the first 30 days of life. In addition, our results suggest that infants were still exposed to low levels of T4 and low iodine intake during a prolonged period. Given the lack of the clinical effect, we hypothesise that very low birth weight infants may need a higher dose of iodine, and the requirements suggested previously may be underestimated.

\section{Conclusion}

The concentrations of thyroid hormones in the neonatal period are related to iodine intake. It is essential that the preterm infants receive the recommended amount of iodine from the first day of life and during all the neonatal period. The adequate intake of iodine ensures that infants can synthesize the required amounts of thyroid hormones during postnatal life, and ensures that the thyroid gland is under the best conditions to cope with the demands of synthesis of hormones during a period of very vulnerable life, in which children have severe diseases and increased demands of their metabolism.

Preterm babies on exclusive formula preparations and with parenteral nutrition are at high risk of iodine deficiency. The volume of food ingested by the infant is small, iodine content in formula preparations is insufficient, parenteral nutrition does not supply enough iodine. Therefore, supplements should be added if iodine intake is found to be inadequate, at least until the milk volume is enough to ensure that the iodine intake meets the RDA. Breast milk appears to be the best source of iodine for the premature infant, because the iodine content is high. International recommendation for iodine intake in lactating women is 250-300 micrograms per day in the form of potassium iodide supplements. It is important to counsel mothers taking these supplements during lactation. Infant formula present in the Spanish market meet the international guidelines of iodine content are a good source of iodine for infants. lodine supplementation via the oral mucosa is feasible in preterm infants during the first weeks after birth, when the volume of milk is low and when they need intravenous nutrition, which often has a low iodine content.

We found that iodine deficiency during the neonatal period is a independent predictor of neurodevelopmental outcomes in ELBW. Multiple factors may contribute to the causes of low neurodevelopmental scores but alterations in thyroid parameters and iodine deficiency play a role. 
Therefore it is important to keep track of those children who had thyroid parameters alterations during the neonatal period.

There is insufficient evidence from controlled clinical trials to determine whether the use of oral iodine for the treatment of preterm infants with transient hypothyroxinaemia results in changes in neurodevelopmental impairments.

Further research is required to determine what type of iodine preparation, timing and duration of treatment is required.

\section{References}

1. Zimmermann MB. The role of iodine in human growth and development. Semin Cell Dev Biol. 2011; 22: 645-652.

2. Bernal J, Nunez J. Thyroid hormones and brain development. Eur J Endocrinol. 1995; 133: 390-398.

3. Morreale De Escobar G, Obregon MJ, Del Rey FE. Maternal thyroid hormones early in pregnancy and fetal brain development. Best Pract Res Clin Endocrinol Metab. 2004; 18: 225-248.

4. De Vries LS, Heckmatt JZ, Burrin JM, Dubowitz LM, Dubowitz V. Low serum thyroxine concentrations and neural maturation in preterm infants. Arch Dis Child. 1986; 61: 862-866.

5. Van Wassenaer AG, Kok JH, Dekker FW, De Vijlder JJM. Thyroid function in very preterm infants: influences of gestational age and disease. Pediatr Res. 1997; 42; 604-609.

6. Fisher DA, Klein AH. Thyroid development and disorders of thyroid function in the newborn. $\mathrm{N}$ Engl $\mathrm{J}$ Med. 1981; 304: 702-712.

7. Morreale De Escobar G, Ares S. The hypothyroxinemia of prematurity. J Clin Endocrinol Metab. 1998; 83: 713-715.

8. La Gamma EF, Van Wassenaer AG, Ares S, Golombek SG, Kok JH, Quero J, et al. Phase 1 trial of 4 thyroid hormone regimens for transient hypothyroxinemia in neonates of <28 weeks' gestation. 2009; 124: 258-268.

9. Van Wassenaer-Leemhuis A, Ares S, Golombek S, Kok J, Paneth N, Kase J, et al. Thyroid Hormone Supplementation in Preterm Infants Born Before 28 Weeks Gestational Ageand Neurodevelopmental Outcome at Age 36 Months. 2014; 24: 1162-1169.

10. Ares S, Quero J, Morreale De Escobar G, Spanish Preterm Thyroid Group. lodine during the neonatal period: too little, too much? J Pediatr Endocrinol Metab. 2007; 20: 163-166.

11. Ares S, Quero J, Morreale De Escobar G. Neonatal iodine deficiency: Clinical Aspects. J Pediatr Endocrinol Metab. 2005; 18: 1257-1264.

12. Ares S, Quero J, Duran S, Presas MJ, Herruzo R, Morreale De Escobar G. lodine content of infant formulas and iodine intake of premature babies: high risk of iodine deficiency. Arch Dis Child. 1994; 71: 184-191. 
13. Ares S, Garcia P, Quero J, Morreale De Escobar G. lodine intake and urinary excretion in premature infants born after less than 30 weeks of gestation. J Clin Ped Endocrinol. 2004; 17: 509.

14. Ares S, Quero J, Morreale De Escobar G.Neonatal iodine deficiency: clinical aspects. J Pediatr Endocrinol Metabol. 2005; 18: 1257-1264.

15. Ares S, Escobar-Morreale HF, Quero J, Duran S, Presas MJ, Herruzo R, et al. Neonatal hypothyroxinemia: effects of iodine intake and premature birth. J Clin Endocrinol Metab. 1997; 82: 1704-1712.

16. Ares S, Garcia P, Quero J, Morreale De Escobar G. Parameters of thyroid function in premature infants born at 25-30 weeks of gestation and their relation to pathology and medication during the neonatal period. J Clin Ped Endocrinol. 2004; 17: 511.

17. Biswas S, Buffery J, Enoch H, Martin Bland J, Walters D, Markiewicz M. A longitudinal assessment of thyroid hormone concentrations in preterm infants younger than 30 weeks' gestation during the first 2 weeks of life and their relationship to outcome. 2002; 109: 222-227.

18. Reuss ML, Paneth N, Pinto-Martin JA, Lorenz JM, Susser M. The relation of transient hypothyroxinemia in preterm infants to neurologic development at two years of age. $\mathrm{N}$ Engl $\mathrm{J}$ Med. 1996; 334: 821-827.

19. Ares S, Quero J, Diez J, Morreale De Escobar G. Neurodevelopment of preterm infants born at 28 to 36 weeks of gestational age: the role of hypothyroxinemia and long-term outcome at 4 years. $\mathrm{J}$ Pediatr Endocr Met. 2011; 24: 897-902.

20. Den Ouden AL, Kok JH, Verkerk PH, Brand R, Verloove-Vanhorick SP. The relation between neonatal thyroxine levels and neurodevelopmental outcome at age 5 and 9 years in a national cohort of very preterm and/or very low birth weight infants. Pediatr Res. 1996; 39: 142-145.

21. Lucas A, Morley R, Fewtrell MS. Low triiodothyronine concentration in preterm infants and subsequent intelligence quotient (IQ) at 8 year follows up. 1996; 312: 1132-1133.

22. Williams F, Hume R, Ogston S, Brocklehurst P, Kayleigh M, I2S2 team, et al. A Summary of the lodine Supplementation Study Protocol (I2S2): A UK Multicentre Randomised Controlled Trial in Preterm Infants. 2014; 105: 282-289.

23. Van Wassenaer AG, Kok JH, De Vijlder JJ, Briet JM, Smit BJ, Tamminga P, et al. Effects of thyroxine supplementation on neurologic development in infants born at less than 30 weeks' gestation. $\mathrm{N}$ Engl J Med. 1997; 2; 336: 21-6.

24. Ibrahim M, Morreale De Escobar G, Visser TJ, Duran S, Van Toor H, Strachan J, et al. lodine deficiency associated with parenteral nutrition in extreme preterm infants. Arch Dis Child. 2003; 88: 56-57.

25. Rogahn J, Ryan S, Wells J, Fraser B, Squire C, Wild N, Hughes A, Amegavie L. Randomised trial of iodine intake and thyroid status in preterm infants Arch Dis Child Fetal Neonatal Ed 2000;83:F86F90

26. Francis-Williams J, Yule W. The Bayley Infant Scales of Mental and Motor Development. An exploratory study with an English sample. Dev Med Child Neurol. 1967; 9: 391-401. 
27. Ares S, Saenz-Rico B, Diez JMD and Bernal J. lodine Intake, Thyroid Function and Neurodevelopmental Outcome in Preterm Infants from 24 to 30 Weeks Gestation. J Pediatri Endocrinol. 2016; 1(3): 1011.

28. Benotti J, Benotti N. Protein-bound iodine, total iodine and butanol-extractable iodine by partial automation. 1963; 9: 408-416.

\section{Tables}

\begin{tabular}{|c|c|c|}
\hline Characteristics & $\begin{array}{l}\text { Control group } \\
n=47 \text { subjects }\end{array}$ & $\begin{array}{l}\text { Iodine supplemented group } \\
\mathrm{n}=47 \text { subjects }\end{array}$ \\
\hline Birth Weight (g) & $997.72(285.8 ; 42.1)$ & $1050.5(232.3 ; 35.0)$ \\
\hline Heigh (cm) & $36.18 \quad(3.8 ; 0.6)$ & $35.62 \quad(3.5 ; 0.6)$ \\
\hline Head circumference $(\mathrm{cm})$ & $25.10(2.9 ; 0.4)$ & $25.75 \quad(1.9 ; 0.3)$ \\
\hline Gestational Age (weeks) & $28.70(2.6 ; 0.3)$ & $28.82 \quad(2.2 ; 0.3)$ \\
\hline Small for gestational age (SGA) ( $<10^{\text {th }}$ percentile at birth) & 8 & 9 \\
\hline $\begin{array}{l}\mathrm{TSH}(\mathrm{mIU} / \mathrm{L}) \text { at birth } \\
\mathrm{TT}_{4}(\mu \mathrm{g} / \mathrm{dl}) \text { at birth }\end{array}$ & $\begin{array}{l}1.437(1.3 ; 0.2) \\
5.9(2.7 ; 0.4)\end{array}$ & $\begin{array}{l}1.1(0.8 ; 0.1) \\
5.3(2.3 ; 0.4)\end{array}$ \\
\hline C-section / vaginal delivery & $31 / 16$ & $35 / 12$ \\
\hline Hyaline membrane disease & 27 & 30 \\
\hline Cerebral intraventricular hemorrhage ( Grade III and IV lesions) & 13 & 11 \\
\hline Anemia & 33 & 36 \\
\hline Patent ductus arteriosus & 19 & 22 \\
\hline Retinopathy (grade 3) & 3 & 0 \\
\hline
\end{tabular}

TABLE 1 : Neonatal characteristics of study population (mean (SD; SEM) by control group vs supplemented group

Table 2 : Description of Iodine intake/Kg/day 


\begin{tabular}{|l|l|l|l|l|}
\hline Iodine intake/Kg/day & & & & \\
& group & Medium & Std.Deviation & Std.Error \\
\hline Day 7 & 1 & 10,348 & 7,9607 & 1,3858 \\
\hline & 2 & 43,291 & 8,5648 & 1,5637 \\
\hline day 15 & 1 & 22,194 & 12,5001 & 2,1129 \\
\hline & 2 & 52,757 & 11,8873 & 2,1350 \\
\hline day 21 & 1 & 26,674 & 14,0465 & 2,4452 \\
\hline & 2 & 53,514 & 11,6721 & 2,0964 \\
\hline day30 & 1 & 28,735 & 8,4298 & 1,5391 \\
\hline & 2 & 57,673 & 9,3213 & 1,7309 \\
\hline day 60 & 1 & 29,280 & 4,7744 & 1,1253 \\
\hline & 2 & 58,124 & 2,6498 & 0,9368 \\
\hline At discharge & 1 & 31,075 & 4,2111 & 0,7563 \\
\hline & 2 & 61,173 & 2,9436 & 0,5887 \\
\hline
\end{tabular}

Due to technical limitations, Table 3 is only available as a download in the supplementary files section.

\section{Figures}




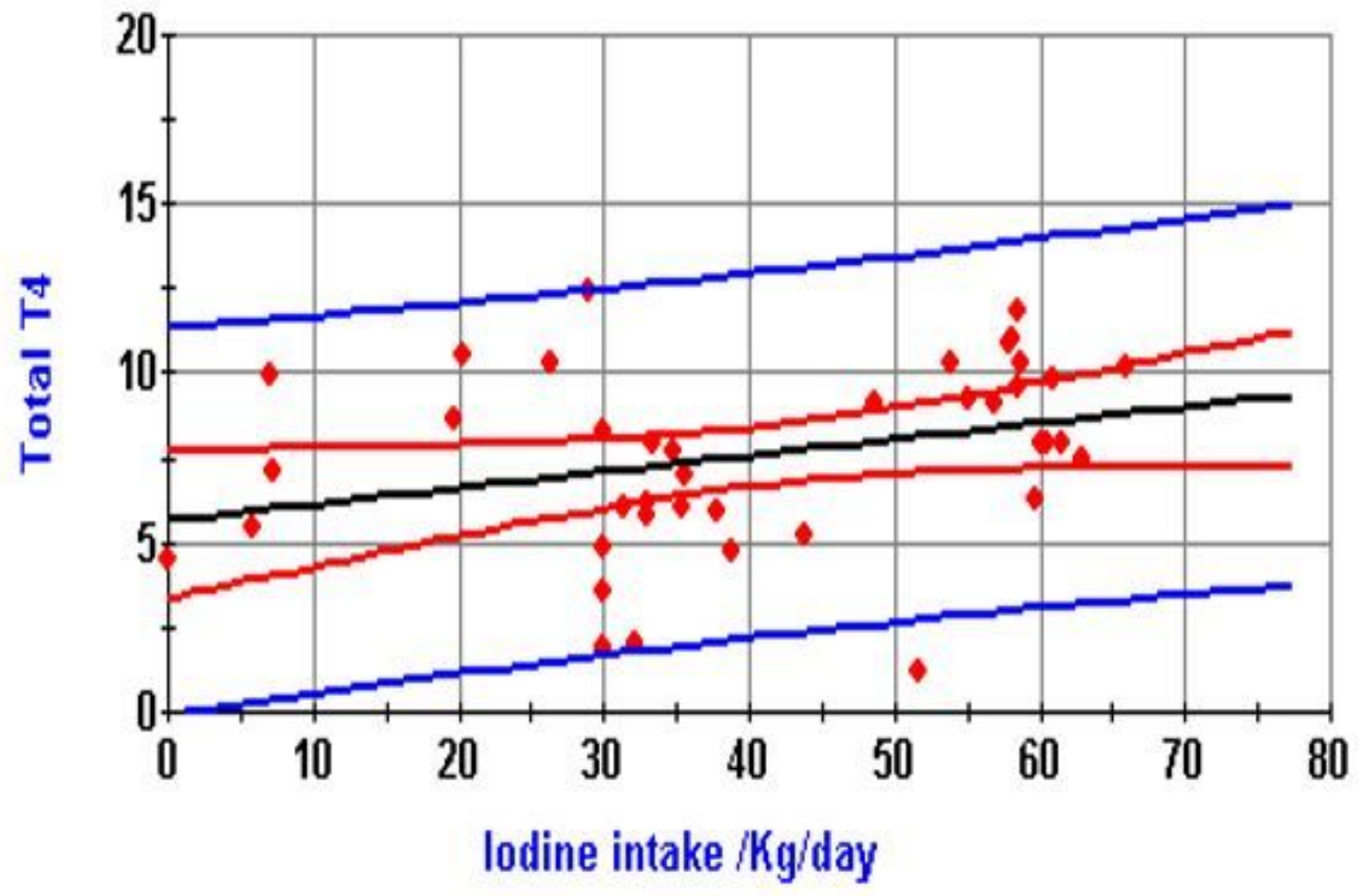

Figure 1

Total T4 serum concentrations related to iodine intake in very preterm infants

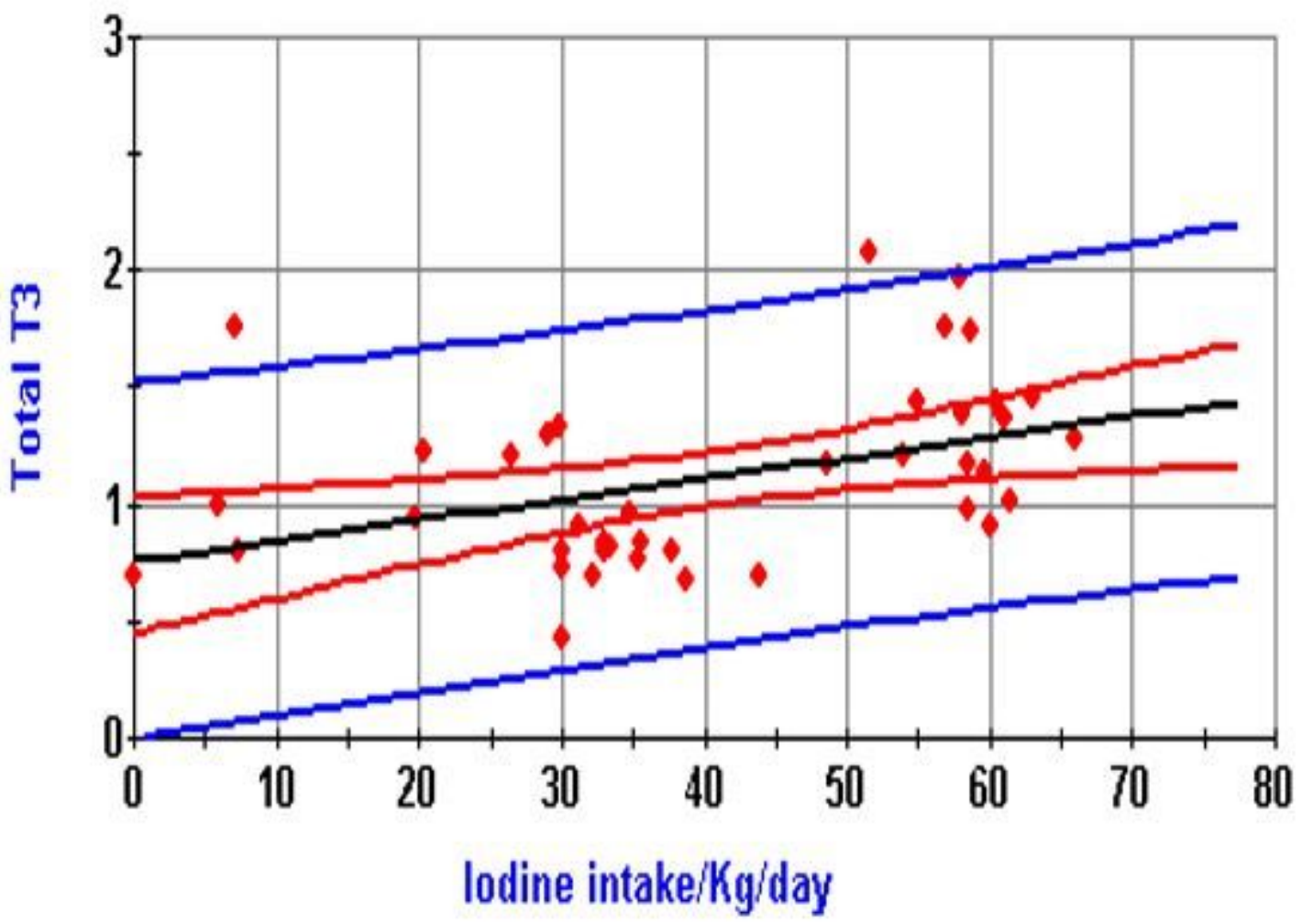


Figure 2

Total T3 serum concentrations related to iodine intake in very preterm infants

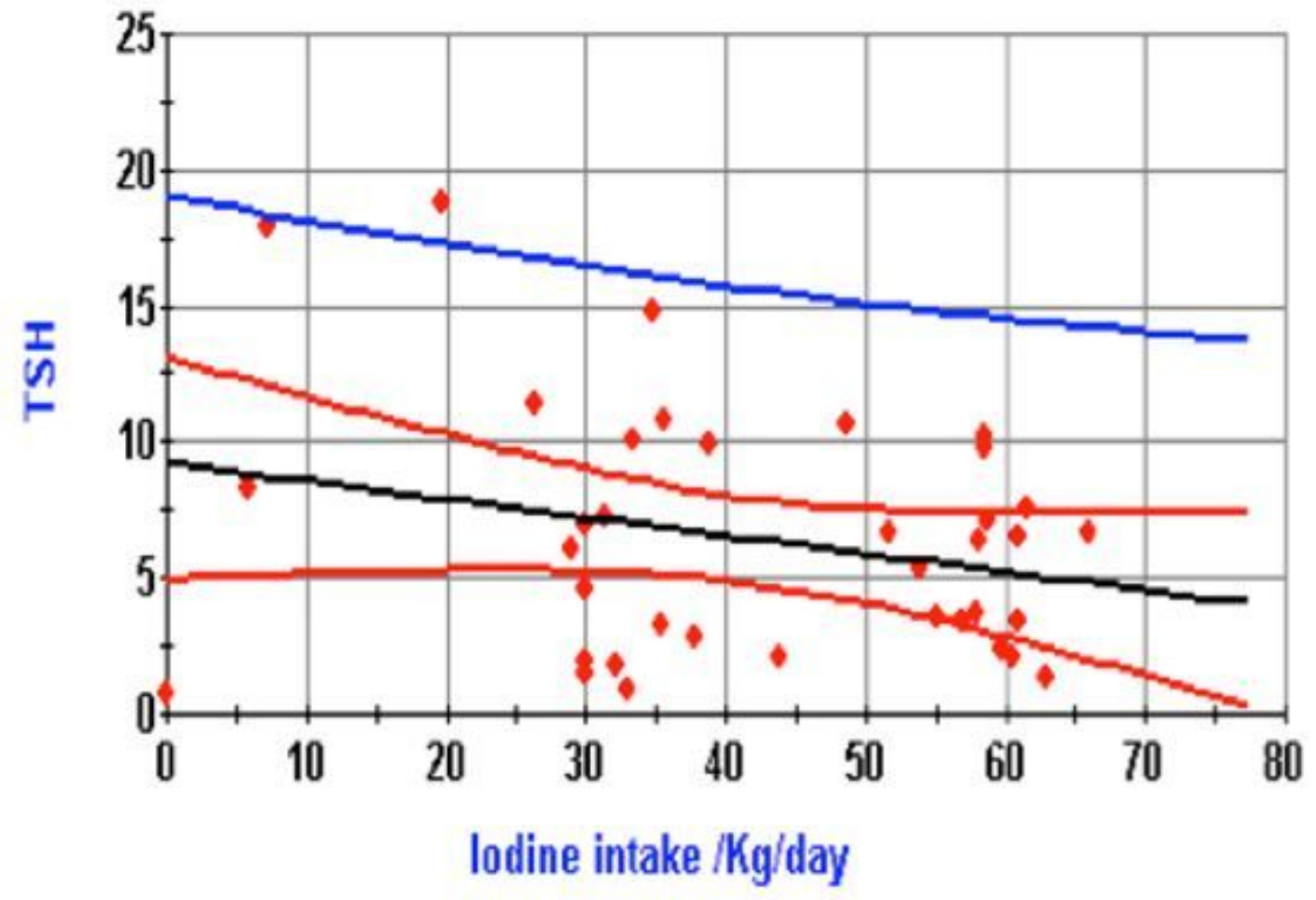

Figure 3

TSH serum concentrations related to iodine intake in very preterm infants

\section{Supplementary Files}

This is a list of supplementary files associated with this preprint. Click to download.

- Table3.docx 